\title{
A nonlinear optimization model on the reinforcement length of a modular block wall by varying surcharge and soil strength parameters
}

\author{
Vuttichai Chatpattananan ${ }^{1 *}$, and Thanadol Kongsomboon ${ }^{1}$ \\ ${ }^{1}$ Department of Civil Engineering, Faculty of Engineering, King Mongkut's Institute of Technology Ladkrabang, Bangkok, Thailand
}

\begin{abstract}
This study proposes a nonlinear optimization approach in designing a modular block wall which is a type of the mechanical stabilized earth wall. A nonlinear optimization model is proposed based on minimizing the reinforcement length where the constraints considered are the external stability and the internal stability. The optimum reinforcement length can be determined based on available soil strength parameters and the maximum surcharge. This study also includes the parametric study of the reinforced soil, retained soil, and foundation soil by varying the ranges of the wall height, surcharge, and soil strength parameters in density and friction angle to see the behaviours of the aforementioned external stability and internal stability. This can be beneficial in designing this modular block wall encountering a poor soil condition or a large amount surcharge
\end{abstract}

\section{Introduction}

Mechanically stabilized earth wall or MSE wall, is a retaining wall that uses soil with reinforcement in adding tension. With rigid facing units, MSE wall can set vertically not like reinforced soil slope (RSS) that can set slope up to 70 degrees. Two types of MSE walls are commonly used. One is segmental precast concrete panel (SPCP) that uses metal strips as reinforcements and precast concrete panel as the facing unit. The other is modular block wall (MBW) that uses geogrid as reinforcements and modular block as facing units as shown in Fig. 1.

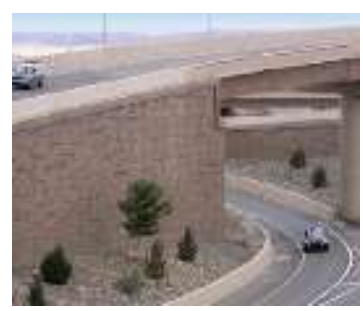

SPRC

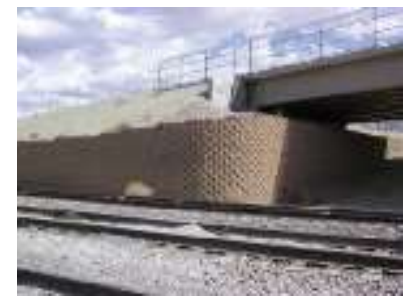

MBW
Fig. 1. MSE Wall Types (FHWA-NHI-00-043) for

An MSE wall needs to resist the failure modes in external stability, internal stability, and global stability. External stability requires this rigid body MSE wall to pass the safety factor in sliding, overturning, and bearing capacity. Internal stability prevents the failure in inside the MSE wall by setting factors of safety in rupture and safety in pullout. Global stability considers all other failure that may occurs anywhere especially outside the MSE wall.

Designing an MSE mainly is to specify the reinforcement length, reinforcement spacing, and soil strength property. [1] gives a preliminary reinforcement length $(L)$ should be $0.7 H$ and $2.5 \mathrm{~m}$ where $H$ is the height of the wall. [2, 3] recommends $L / H$ at 0.7 where [4] recommends at $0.6 L / H$. Also [1] recommends $L / H$ to be less than 1.1. However, designing an MSE wall faces many varying variables, especially the soil strength parameters and the imposed surcharge load. Some studies introduce optimization based approach in designing MSE wall such as [5-7]. [5] uses optimization in finding minimum cost to design a segmental precast concrete with metal strip reinforcements. Simulation is also utilized in [5] to assist in approximating the nonlinear optimum solution. [8] uses an optimization approach on cost. [9] introduces an advanced technique in finding a nonlinear optimization model for MSE wall design parameters. This paper rather investigates the behaviour of varying parameters in designing an MBW first then utilizing a nonlinear optimization model via GAMS nonlinear software to minimize the geogrid reinforcements satisfying the constraints in external stability and internal stability.

\section{Optimizing reinforcement length for a modular block wall}

\footnotetext{
"Corresponding author: vuttich@hotmail.com
} 
Designing a segmental precast concrete panel is different from designing a MBW only the differences in pullouts due to the difference of the potential failure surface in the internal stability as shown later in Fig. 3. For illustration, only MBW that uses geogrid as reinforcement is shown in this study. Also, the optimization will consider only the external stability and internal stability based on FHWA [1], the global stability that uses limit equilibrium method (LEM) is omitted here. LEM can be analyzed with many available software.

Based on [1], calculating factors of safety (FS) are shown in Fig. 2 as follows:

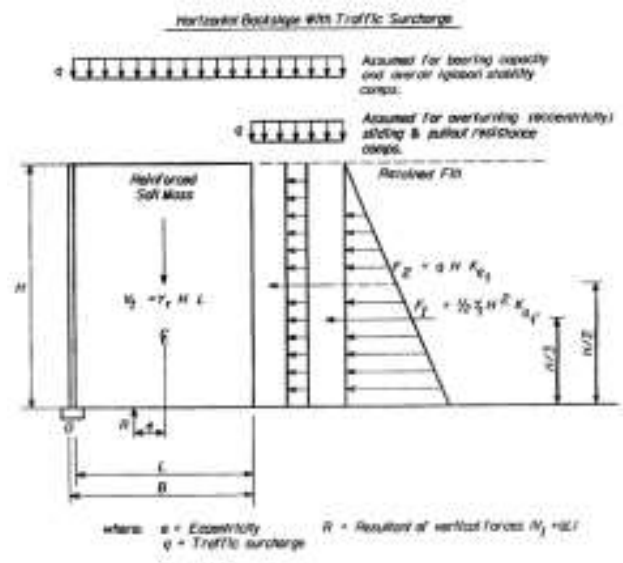

Fig. 2. MSE wall loads [1]

To formulate an optimizing model from Fig. 2, the decision variables can be classified as 3 groups which are as follows. Group 1 decision variables are wall height, surcharge loads, and soil strength parameters. Group 2 decision variables are external stability involving the factors of safety for sliding, overturning, eccentricity, and bearing. Group 3 decision variables are internal stability factors of safety for rupture and pullout.

Group 1 decision variables are denoted as wall height $H \mathrm{~m}$, geogrid length $L \mathrm{~m}$, surcharge load $q \mathrm{kN} / \mathrm{m}^{2}$, soil parameters are density $\gamma \mathrm{kN} / \mathrm{m}^{3}$, cohesion $c \mathrm{kN} / \mathrm{m}^{2}$, and internal friction angle $\phi$ degree. The active earth pressure coefficient is $K_{a}=\tan ^{2}(45-\emptyset / 2)$. Reinforced soil parameters are denoted as $\gamma_{r}, c_{r}, \emptyset_{r}, K_{a r}$. Retained (backfill) soil parameters are denoted as $\gamma_{b}, c_{b}, \emptyset_{b}$. Foundation soil are denoted as $\gamma_{f}, c_{f}, K_{a f}$. For loads, vertical fill $V_{1}=\gamma_{r} H L \mathrm{kN} / \mathrm{m}$, vertical surcharge $V_{2}=q L$ $\mathrm{kN} / \mathrm{m}$, horizontal retained soil $F_{1}=0.5 \gamma_{b} H^{2} K_{a f} \mathrm{kN} / \mathrm{m}$, horizontal surcharge $F_{2}=q H K_{a f} \mathrm{kN} / \mathrm{m}$.

Group 2 decision variables are external stability factors of safety (FS) including sliding, overturning, eccentricity, and bearing. The sliding FS is

$$
F S_{S}=V_{1} \tan \left(\min \left\{\varnothing_{r}, \emptyset_{f}\right\}\right) /\left(F_{1}+F_{2}\right) \geq 1.5
$$

The overturning moment $M_{O}=F_{1} H / 3+F_{2} H / 2$ kN-m, resisting moment $M_{R O}=V_{1} L / 2 \mathrm{kN}-\mathrm{m}$, bearing moment $M_{R B P}=V_{1} L / 2+V_{2} L / 2 \mathrm{kN}$-m, then the overturning FS is

$$
F S_{O}=M_{R O} / M_{O} \geq 2
$$

For eccentricity,

$$
e=L / 2-\left(M_{R B P}-M_{O}\right) /\left(V_{1}+V_{2}\right) \leq L / 6
$$

The bearing capacity of foundation soil, where maximum bearing pressure is $\sigma_{V}=\left(V_{1}+V_{2}\right) /(L-2 e)$ $\mathrm{kN} / \mathrm{m}^{2}$, ultimate bearing capacity, $\sigma_{u l t}=c_{f} N_{c}+0.5(L-$ 2e) $\gamma_{f} N_{\gamma} \mathrm{kN} / \mathrm{m}^{2}$ and the bearing FS is

$$
F S_{b}=\sigma_{u l t} / \sigma_{v} \geq 2.5
$$

The bearing capacity factors are assumed as follows. $N_{q}=e^{\pi \tan \emptyset_{f}} \tan ^{2}\left(45+\emptyset_{f} / 2\right), \quad N_{c}=\left(N_{q}-1\right) \cot \emptyset_{f}$, $N_{\gamma}=\left(N_{q}-1\right) \tan \left(1.4 \emptyset_{f}\right)$.

Group 3 decision variables are internal stability factors of safety. With maximum tensile strength, $T_{\max }$ of geogrid at layer $i$ is $T_{\max -i}=\sigma_{H} V_{i}$, the horizontal stress $\sigma_{H}=$ $K_{a r}\left(\gamma_{b} d_{i}+q\right), T_{\max -i} \leq T_{a i}$ where $T_{a i}$ is the allowable tensile strength of geogrid at layer $i . V_{i} \mathrm{~m}^{2}$ is the grid area of geogrid at layer $i$ at depth $d_{i} \mathrm{~m}, V_{1}=d_{1}+\left(d_{2}-d_{1}\right) / 2$ for the top first layer, $V_{i}=\left(d_{i}-d_{i-1}\right) / 2+\left(d_{i+1}-\right.$ $\left.d_{i}\right) / 2$ for layer $i$ to $n-1 . V_{n}=\left(H-d_{n}\right)+\left(d_{n}-d_{n-1}\right) / 2$ for the bottom layer.

For pullout, the active zone length at layer $i$ is $L_{a i}=$ $\left(H-d_{i}\right) \tan \left(45-\emptyset_{r} / 2\right)$. The resistant zone length at layer $i$ is $L_{e i} \geq 1.5 T_{\max -i} /\left(C \tan \emptyset_{r} C_{R} \gamma_{r} d_{i} R_{c} \alpha\right) \geq 1 \mathrm{~m}$ $R_{c}=1.0$ is \% coverage of reinforcement ranging from 0.71 to 1.0. $C_{R}=0.8$ is the interaction pullout coefficient derived a product, $C=2$ for geogrid, $\alpha=1.0$ is the scale effect correction factor , $L_{T}=L_{a}+L_{e}$ is the total length of geogrid at layer $i$ where all at all layer $L_{T} \leq L$. The pullout factor of safety for layer $i$ is

$$
F S_{P i}=L_{e} C \tan \emptyset_{r} C_{R} \gamma_{r} d_{i} R_{c} \alpha / T_{\max -i} \geq 1.5
$$

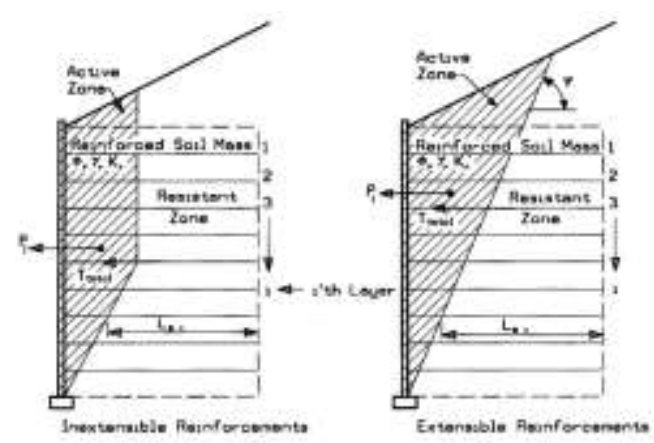

Fig. 3. Active zone and resistant zone of MBW wall [1]

In conclusion, the nonlinear optimization model is as follows.

$$
\begin{array}{ccc}
\text { Min } & L \\
\text { st. } & F S_{S} & \geq F S_{S a} \\
& F S_{O} & \geq F S_{O a} \\
e & \leq L / 6 \\
& =F S_{B} & \geq F S_{B a} \\
& F S_{P 1} & \geq F S_{P 1 a}
\end{array}
$$


The constraint 1 to constraint 5 in the optimization model (6) are from the aforementioned (1) to (5). Following FHWA, allowable factors of safety for sliding $(=1.5)$, overturning $(=2,0)$, bearing $(=2,5)$, resistant zone pullout length $(=1.5)$. Also from Fig. 3, the pullout lengths are largely dominated by the top layer geogrid where the active zone length is largest at the top layer.

From the FHWA MBW example [1], where $H=9 \mathrm{~m}, L$ $=7.5 \mathrm{~m}, q=11.97 \mathrm{kN} / \mathrm{m}$, reinforced soil $\gamma_{r}=19.6 \mathrm{kN} / \mathrm{m}^{3}, c_{r}=$ $0 \mathrm{kN} / \mathrm{m}^{2}, \emptyset_{r}=34$, retained soil $\gamma_{b}=19.6 \mathrm{kN} / \mathrm{m}^{3}, c_{b}=0 \mathrm{kN} / \mathrm{m}^{2}$, $\emptyset_{b}=30$, foundation soil $\gamma_{r}=19.6 \mathrm{kN} / \mathrm{m}^{3}, c_{f}=0 \mathrm{kN} / \mathrm{m}^{2}, \emptyset_{f}=$ 30. For the reinforcement layer depth, $d_{1}=0.47 \mathrm{~m}, d_{2}=$ $1.07 \mathrm{~m}$. For this FHWA example, GAMS Software with NLP model is used to obtain the nonlinear optimization result for the reinforcement. If the minimum reinforcement constraint at $0.7 \mathrm{~L} / \mathrm{H}$ is relaxed, the optimum reinforcement length is shortened to $0.62 \mathrm{~L} / \mathrm{H}$ where the pullout is bounding constraint with the eccentricity as shown in Table I.

Table 1. Nonlinear optimization results on FHWA example

\begin{tabular}{|l|c|c|c|}
\hline \multicolumn{1}{|c|}{ Items } & $\begin{array}{c}\text { Allowable } \\
\text { FHWA FS }\end{array}$ & $\begin{array}{c}\text { FHWA } \\
\text { Example }\end{array}$ & $\begin{array}{c}\text { Nonlinear } \\
\text { Optimization }\end{array}$ \\
\hline$H(\mathrm{~m})$ & 9 & 9 & 9 \\
$L(\mathrm{~m})$ & & 7.5 & 5.54 \\
$L / H$ & 0.7 & 0.83 & 0.62 \\
Sliding FS & 1.5 & 2.54 & 1.88 \\
Overturning FS & 2.5 & 5.19 & 2.83 \\
Eccentricity (m) & & 0.68 & 0.92 \\
Allowable Eccentricity (m) & L/6 & 1.25 & 0.92 \\
Bearing FS & 2.5 & 5.87 & 2.89 \\
Tmax at top layer (kN/m) & & 4.61 & 4.61 \\
Pullout Length at top layer(m) & & 5.54 & 5.54 \\
\hline
\end{tabular}

\section{Parametric study on an MBW}

To see the effect on varying parameters effecting this MBW reinforcement lengths, [6] suggests the ranges of soil strength parameters in density, cohesion, and internal friction angle. For simplicity, the soil parameter varied in this study is only the soil internal friction angle $(\phi)$ ranging from 22 to 45 degree where soil density ( $\gamma$ ) ranging from $17-22 \mathrm{kN} / \mathrm{m}^{3}$ from [10] is set to be constant at $19.6 \mathrm{kN} / \mathrm{m}^{3}$ since soil internal friction angle is normally implies its density. In addition, this study set soil cohesion to be zero since a soil type with cohesion and internal friction angle can be roughly converted to internal friction angle only.

Fig. 4 to Fig. 8 shows the effects on varying wall heights and surcharge on the aforementioned FHWA MBW wall example. Fig. 6 (left) shows that increasing wall height almost has no effect to $L / H$ eccentricity at all, and has effect to $L / H$ of the rest including sliding, overturning, bearing, and pullout if surcharge increased significantly to $50 \mathrm{kN} / \mathrm{m}^{2}$, equivalent to 5 tons $/ \mathrm{m}^{2}$ or $2.5 \mathrm{~m}$ of wall weight height, as shown in the figures. The result is similar to weak soil strengths with low internal friction angles where not only eccentricity but overturning have no effect their $L / H$. Also as shown in Fig. 7 (right), wall height is limited by bearing $L / H$ under weak soil condition.
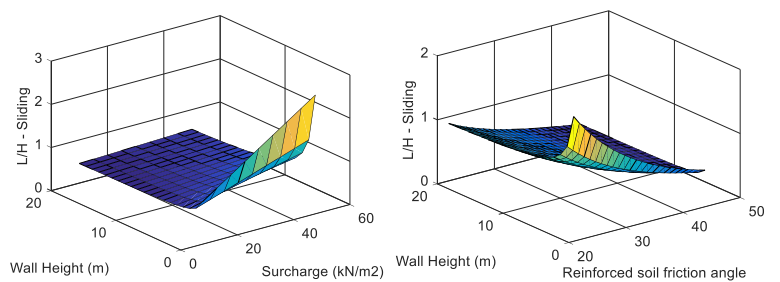

Fig. 4. $L / H$ Sliding by varying $H-q$ (left) and $H_{-} \phi$ (right)
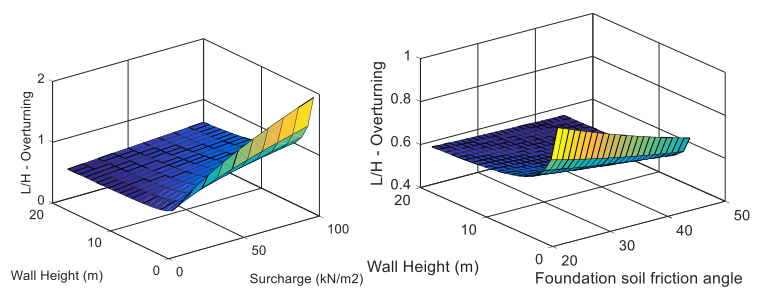

Fig. 5. $L / H$ Overturn by varying $H-q$ (left) and $H-\phi$ (right)
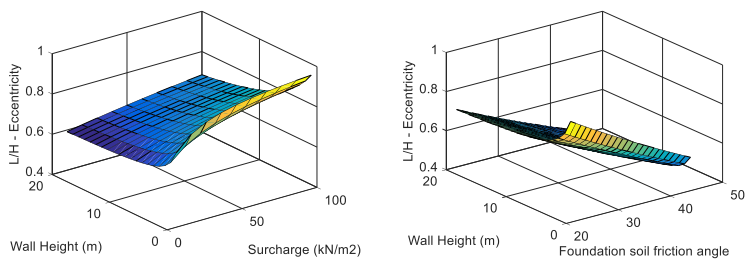

Fig. 6. $L / H$ eccentricity by varying $H-q$ (left) and $H-\phi$ (right)
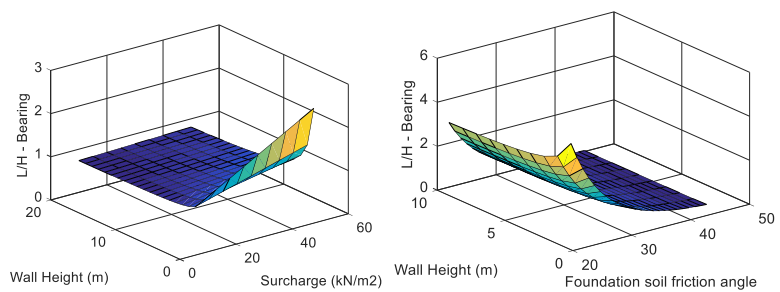

Fig. 7. $L / H$ Bearing by varying $H-q$ (left) and $H_{-} \phi$ (right)
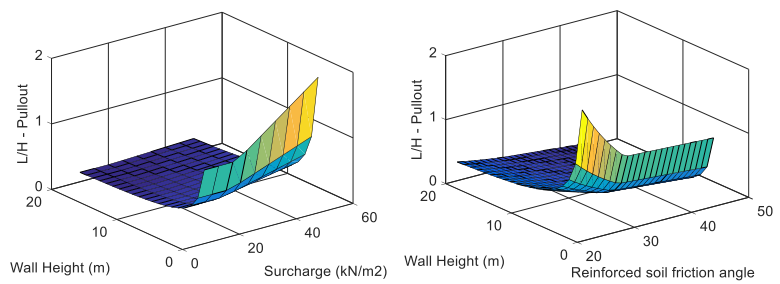

Fig. 8. $L / H$ Pullout by varying $H_{-} q$ (left) and $H_{-} \phi$ (right)

\section{Optimizing based on site limitation}

An example of using this nonlinear optimization is elucidated here. FHWA MBW example is used here for illustration that the wall height is $9 \mathrm{~m}$ and surcharge is $q=$ $11.97 \mathrm{kN} / \mathrm{m}$. Suppose that an MBW wall project facing a difficulty in the limitation under the weak soil strength condition. The soil strength properties for reinforce soil, retained soil, and foundation soil possess density from 17 $-18 \mathrm{kN} / \mathrm{m}^{3}$ and internal friction angles are from $22-23$. 
Instead of limiting the geogrid length to $1.1 \mathrm{~L} / \mathrm{H}$, this project is rather temporary and allow the factors of safety for sliding, overturning, and bearing to be just greater than 1.0 and eccentricity is less than $L 6$. The nonlinear optimization model is shown in (7) where its result is shown in Table 2. From Table $2, L / H$ is 0.76 . Table 2 also shows the result that strictly design follows FHWA that yields $L / H$ at 0.85 . This result in reducing $L / H$ is rather useful when some part of the constructed MSE wall facing weak soil condition the is much deviated from the soil investigation report.

$\begin{array}{cccc}\text { Min } & L & & \\ \text { st. } & F S_{S} & \geq & F S_{S a} \\ & F S_{O} & \geq & F S_{O a} \\ & e & \leq & L / 6 \\ & F S_{B} & \geq & F S_{B a} \\ & F S_{P 1} & \geq & F S_{P 1 a} \\ & 17 \leq & \gamma_{r}, \gamma_{b}, \gamma_{f} & \leq 18 \\ & 22 \leq & \emptyset_{r}, \emptyset_{b}, \emptyset_{f} & \leq 23 \\ & F S_{S a}, F S_{O a}, F S_{B a} & \geq & 1.0\end{array}$

The optimization model is shown in (7) where constraint 1 to 5 are from (1) to (5) same as the optimization model (6). The adding constraint 6 and constraint 7 are from the relaxing condition of soil strength condition from the site limitation. The constraint 8 is from the assumed relaxing design criteria.

Table 2. Relaxing optimization results on weak soil.

\begin{tabular}{|l|c|c|c|c|}
\hline \multirow{2}{*}{\multicolumn{1}{|c|}{ Items }} & \multicolumn{2}{|c|}{ Relaxing FS } & \multicolumn{2}{c|}{ FHWA FS } \\
\cline { 2 - 5 } & Actual & Minimum & Actual & Minimum \\
\hline$H(\mathrm{~m})$ & 9 & & 9 & \\
$L(\mathrm{~m})$ & 6.82 & & 7.61 & \\
$L / H$ & 0.76 & & 0.85 & \\
Sliding FS & 1.23 & 1.0 & 1.5 & 1.5 \\
Overturning FS & 3.25 & 1.0 & 4.20 & 2.0 \\
Eccentricity (m) & 0.98 & $\mathrm{~L} / 6$ & 0.84 & $\mathrm{~L} / 6$ \\
Bearing FS & 1.94 & 1.0 & 2.74 & 2.5 \\
Tmax at top layer (kN/m) & 6.73 & & 7 & \\
Pullout Length at top layer(m) & 6.82 & 1.0 & 8 & 1.5 \\
\hline
\end{tabular}

Another application is for a multi-tiered MBW project that the bottom wall needs to support the weight of the upper wall that is considered as a surcharge. In this case the surcharge is rather large. To illustrate, suppose that this FHWA MBW wall has a surcharge of $100 \mathrm{kN} / \mathrm{m}^{2}$ which is roughly about $5 \mathrm{~m}$ of the upper wall height resting on the bottom wall. By using the nonlinear optimization model in (7), the result is shown in Table III. The solution is to use the maximum $L / H$ at 1.1 with unlimited soil strength parameters with maximum soil density at $22 \mathrm{kN} / \mathrm{m}^{3}$ and friction angle at 45 . The solution in Table III on the left takes the maximum values of the density and friction angle for the reinforced soil which is practically impossible. Suppose at the construction site limits the soil strength parameters at the maximum density at $20 \mathrm{kN} / \mathrm{m}^{3}$ and friction angle at 34, the solution in Table 3 in limiting soil strength parameters takes the maximum density and friction angle for the reinforced soil and strengthen the friction angle for the foundation soil.
Table 3. Optimization Soil Strength Parameters.

\begin{tabular}{|l|c|c|c|c|}
\hline \multirow{2}{*}{\multicolumn{1}{|c|}{ Items }} & \multicolumn{2}{|c|}{ Unlimited Soil Strengths } & \multicolumn{2}{c|}{ Limited Soil Strength } \\
\cline { 2 - 5 } & Actual FS & Minimum & Actual FS & Minimum \\
\hline$H(\mathrm{~m})$ & 9 & & 9 & \\
$L(\mathrm{~m})$ & 9.9 & & 9.9 & \\
$L / H$ & 1.10 & & 1.10 & \\
Sliding FS & 1.50 & $\geq 1.5$ & 1.50 & $\geq 1.5$ \\
Overturning FS & 4.77 & $\geq 2$ & 4.77 & $\geq 2$ \\
Eccentricity (m) & 0.69 & $\leq 1.65$ & 0.67 & $\leq 1.65$ \\
Bearing FS & 2.50 & $\geq 2.5$ & 2.58 & $\geq 2.5$ \\
Tmax at top layer $(\mathrm{kN} / \mathrm{m})$ & 14.27 & & 23.51 & \\
Pullout Length at top layer(m) & 4.83 & & 8.01 & \\
Reinforced soil density $\left(\mathrm{kN} / \mathrm{m}^{3}\right)$ & 22 & $\leq 22$ & 20 & $\leq 20$ \\
Retained soil density $\left(\mathrm{kN} / \mathrm{m}^{3}\right)$ & 17 & $\leq 22$ & 17 & $\leq 20$ \\
Foundation soil density $\left(\mathrm{kN} / \mathrm{m}^{3}\right)$ & 17 & $\leq 22$ & 17 & $\leq 20$ \\
Reinforced friction angle & 45 & $\leq 45$ & 34 & $\leq 34$ \\
Retained friction angle & 30.07 & $\leq 45$ & 32 & $\leq 34$ \\
Foundation friction angle & 22 & $\leq 45$ & 22 & $\leq 34$ \\
\hline
\end{tabular}

\section{Conclusion}

Employing the nonlinear optimization approach helps facilitating the design of a modular block wall that often facing difficulties such as varying soil strength parameters and maximum surcharge bearable for the bottom wall that needs to support the upper wall that is counted as a surcharge resting on the bottom wall. By limiting the ranges of soil strength parameters in reinforced soil, retained soil, and foundation soil, the minimum geogrid reinforcement length can be determined based on considering only the external stability and internal stability.

\section{References}

1. Federal Highway Administration, FHWA-NHI-OO043, (2001)

2. AASHTO, Standard specifications for highway bridges, (1997)

3. The British Standards Institution, BS8006, (2010)

4. National Concrete Masonry Association, Design manual for segmental retaining walls. 2 ed. (2002)

5. H. Ghiassian, K. Aladini, Asian J. of Civil Engr., V. 10, 6, (2009)

6. D. Leshchinsky, D., V. Kaliakin, P. Bose, J. Collin, Soils and Foundations, Vol. 34, 4, (1994)

7. D. Leshchinsky, C. Vulova, Geosynthetics International, Vol. 8, 4, (2001)

8. P. K. Basudhar, A. Vashistha, K. Deb, A. Dey, Geotech Geol. Eng., 26, (2008)

9. K. N. Manahiloh, M. M. Nejad, M. S. Momeni, Int. J. of Geosynth. and Ground Eng., (2015)

10. R. Obrzud, A. Truty, The hardening soil model -a practical guidebook, (2010) 